\title{
Relação entre os traços sombrios de personalidade e o ceticismo profissional dos auditores independentes
}

\author{
Ronan Reis Marçal \\ https://orcid.org/0000-0002-7922-2364｜Ｅ-mail:m.ronanreis@gmail.com \\ Luiz Alberton \\ https://orcid.org/0000-0001-9611-3859 | E-mail: luiz.alberton@ufsc.br
}

\section{Resumo}

Objetivo: Analisar a influência dos "traços sombrios" de personalidade no ceticismo profissional de auditores independentes do Brasil.

Método: A amostra foi composta de170 auditores independentes com registro ativo no Cadastro Nacional de Auditores Independente (CNAI), sendo os dados analisados mediante estatística descritiva em primeira instância, via análise de regressões estimadas por Mínimos Quadrados Ordinários para a verificação das hipóteses; e por regressões estimadas por Mínimos Desvios Absolutos como medida de análise de sensibilidade. O ceticismo profissional de Hurtt (2010) foi assumido como regressando, ao passo que a "tríade sombria" (narcisismo, maquiavelismo e psicopatia) foi tratada como um conjunto de variáveis de estímulo. Resultados: Os resultados indicam que o narcisismo pode influenciar positivamente o atributo de ceticismo profissional ao alavancar a autoestima e a capacidade de questionamento dos auditores. Já o maquiavelismo e a psicopatia, perante o conjunto de dados analisados, parecem não apresentar qualquer influência positiva no ceticismo profissional, sendo factível até mesmo uma relação inversa em aspectos de autonomia e autoestima, respectivamente.

Contribuições: No âmbito teórico, o estudo apresenta, de forma inédita, os efeitos dos traços de personalidade socialmente indesejáveis no ceticismo profissional dos auditores, além de auxiliar a suprir a lacuna acerca da interdisciplinaridade entre a contabilidade e a psicologia, adentrando especificamente o cerne da auditoria em tal relação. Em termos práticos, a pesquisa promove o entendimento da relevância dos traços de personalidade socialmente indesejáveis para a formação do ceticismo profissional dos auditores, algo útil para as firmas de auditoria ao longo de processos de seleção e treinamento de seus profissionais.

Palavras-chave: Traços sombrios de personalidade; DarkTriad; Ceticismo profissional; Auditoria; Auditores independentes. 


\section{Introdução}

O ceticismo profissional é um dos requisitos básicos de um auditor independente na condução de seus trabalhos, segundo a NBC TA 200 (R1), sendo este termo conceituado como "a postura que inclui uma mente questionadora e alerta para condições que possam indicar possível distorção devido a erro ou fraude e uma avaliação crítica das evidências de auditoria." (CFC, 2016, p. 6).

Tal definição é, segundo Nelson (2009), enquadrada dentro de uma visão neutra, na qual o auditor estaria reunindo e avaliando as evidências sem assumir qualquer viés ex ante. Contudo, Bell, Peecher e Solomon (2005) destacam que dispositivos que versam sobre fraudes - como a NBC TA 240 (R1) - tendem a mudar esta perspectiva, assumindo uma visão de suspeita de presunção, ou seja, os auditores deveriam considerar desde sempre um certo nível de desonestidade dos gestores, a menos que haja provas contrárias disso. Portanto, denota-se que, embora as normas de conduta dos auditores, em geral, adotem o ceticismo como um interesse em comum, há pouca precisão em termos de definição conceitual (Nelson, 2009).

Conquanto coexistam distintos conceitos acerca do ceticismo profissional no âmbito da auditoria, a ideia central é que os auditores não devem aceitar as informações a eles apresentadas em primeira instância, sendo necessária, em vez disso, uma avaliação crítica sobre as evidências existentes para a determinação de uma opinião acerca de um fato (Mubako \& O’Donnell, 2018).

Tal qual nos normativos, na literatura acadêmica o ceticismo profissional do auditor é definido de diferentes maneiras (Nelson, 2009), mas parece ser uníssona a premissa de que o ceticismo deve ser exercido em níveis propícios por auditores independentes para que seus julgamentos profissionais atendam aos propósitos de uma adequada auditoria (Quadackers; Groot \& Wright, 2014; Mubako \& O’Donnell, 2018; Mendes; Niyama \& Silva, 2018). Hurtt (2010), por exemplo, ressalta que não há nenhuma outra esfera profissional onde o ceticismo seja tão relevante quanto na auditoria.

Embora as pesquisas e os órgãos reguladores ressaltem a relevância do ceticismo para o cerne da auditoria, é mister destacar que o ceticismo, por si só, é uma característica de difícil mensuração (Hurtt; Brown-Liburd; Earley \& Krishnamoorthy, 2013; Nolder \& Kadous, 2018). Nessa esteira, autores como Nelson (2009), Hurtt et al. (2013) e Nolder e Kadous (2018) tentaram identificar os antecedentes do ceticismo profissional dos auditores, sendo as características dos auditores (como a motivação, o afeto, a expertise, entre outras) um elemento presente em todas essas pesquisas.

Nessa toada, alguns estudos evidenciam que o ceticismo profissional está relacionado com os traços de personalidade dos auditores, a exemplo de Nelson (2009), Quadackers et al. (2014) e Cohen, Dalton e Harp (2017). Estes estudos, em geral, analisam a referida relação a partir de traços de personalidade tidos como desejáveis, como a conduta ética, a autoconfiança, entre outros. Um exemplo recente desta tendência é a pesquisa de Cunha, Silva, Peyerl e Haveroth (2019), que analisou os efeitos da experiência, consciência, extroversão, amabilidade e neuroticismo no ceticismo profissional dos auditores, e demonstrou a existência de sinais distintos nas relações formadas diante dos traços de personalidade previamente especificados.

Contudo, não há relatos ou evidências empíricas sobre a influência dos traços de personalidade socialmente indesejáveis no ceticismo profissional. Essa lacuna de pesquisa se faz relevante no cenário da auditoria, pois a psicologia tem sugerido que os auditores reportam diferentes interações sociais a depender de suas personalidades, fato que implica uma consequente influência na qualidade dos serviços de auditoria (Hobson; Stern \& Zimbelman, 2020). Estes autores exemplificam essa relação ao explicarem que a interação social de um auditor tende a comprometer seu ceticismo profissional, contudo, alguns traços de personalidade podem vir a mitigar esse risco.

Nesse contexto, esta pesquisa tem como objetivo analisar a influência dos "traços sombrios" de personalidade no ceticismo profissional de auditores independentes do Brasil. 
A perspectiva "sombria" da personalidade dos indivíduos tem sido investigada no cenário contábil a partir da chamada DarkTriad, vide Majors (2016), D’Souza e Lima (2018), D’Souza, Lima, Jones e Carré (2019), Hobson et al. (2020), entre outros. A DarkTriad consiste em um conjunto composto por três características indesejáveis distintas, porém parcialmente correlacionadas, quais sejam: narcisismo, maquiavelismo e psicopatia (Paulhus \& Williams, 2002; Jones \& Paulhus, 2014).

É importante destacar que os três traços de personalidade que compõem a DarkTriad são investigados sob a óptica não patológica, uma vez que não há o intuito de realizar diagnósticos clínicos dos indivíduos (D’Souza \& Lima, 2018). Adicionalmente, cabe ressaltar que a tríade sombria de personalidade, em geral, é prejudicial para as organizações e para a sociedade, contudo, em certos aspectos, esses traços de personalidade podem vir a ser benéficos (Volmer; Koch \& Göritz, 2016). D’Souza e Lima (2018), nessa esteira, apontam a análise do "lado brilhante" da DarkTriad como uma lacuna literária; fato abordado na presente pesquisa diante da esperança de um maior nível de ceticismo profissional dos auditores independentes que apresentem características de maquiavelismo, psicopatia e narcisismo.

E por que é importante analisar a influência de novos elementos sobre o ceticismo profissional dos auditores independentes? A resposta para tal questionamento pode ser obtida, por exemplo, a partir de Olsen e Gold (2018), que apontam o ceticismo profissional como um verdadeiro parâmetro de qualidade dos serviços de auditoria. Conforme a NBC TA 200 (R1), este fato seria derivado do maior poder crítico dos profissionais que possuem tal característica laboral.

Dessa forma, o estudo pretende contribuir em termos práticos no campo da auditoria ao elencar como determinados traços de personalidade (no caso, os sombrios) podem vir a ser basilares para um nível adequado de ceticismo dos auditores. Assim, firmas de auditoria poderiam aplicar previamente testes de personalidade aos futuros candidatos profissionais considerando os elementos observados nesta pesquisa, fato que geraria uma melhor ciência sobre o perfil de funcionário desejado pela empresa.

No espectro teórico, são elencadas inferências sobre uma relação ainda não explorada, dado que apenas os traços de personalidade socialmente desejáveis têm sido investigados de forma conjunta ao ceticismo profissional dos auditores (Nelson, 2009; Quadackers et al., 2014; Cohen et al., 2017). Não obstante, os resultados podem contribuir para o cerne acadêmico ao promover a interdisciplinaridade entre a contabilidade e a psicologia, algo ainda escasso segundo D'Souza e Lima (2018), mas que parece ser relevante no âmbito da auditoria, conforme Hobson et al. (2020).

\section{Referencial Teórico}

Esta seção versa sobre a relevância do ceticismo profissional dos auditores; reporta noções sobre a tríade sombria da personalidade (DarkTriad); e apresenta estudos anteriores que abarcaram a DarkTriad nos cenários da contabilidade e da auditoria. Paralelamente, ao longo do texto, foram desenvolvidas e apresentadas as hipóteses de pesquisa.

\subsection{Ceticismo Profissional dos Auditores}

É no âmbito da auditoria que, segundo Hurtt (2010), o ceticismo profissional se faz mais relevante que em qualquer outro domínio. Nolder e Kadous (2018) parecem corroborar esta argumentação ao explanar que o ceticismo profissional está presente em todos os normativos de auditoria e que a falta de ceticismo seria a raiz das deficiências da auditoria aos olhos dos inspetores. Contudo, esses autores e Hurtt et al. (2013) ressaltam que, apesar da referida importância, o ceticismo profissional ainda apresenta definições inconsistentes. 
Segundo a NBC TA 200 (R1), o ceticismo profissional seria a conduta questionadora do auditor ao longo de seu trabalho que o tornaria mais crítico ao avaliar as evidências de auditoria e, consequentemente, o tornaria mais apto a identificar possíveis distorções derivadas de erros ou fraudes. Nesse sentido, o ceticismo profissional é um balizador da qualidade dos serviços de auditoria (Olsen \&Gold, 2018). Isso ocorre porque uma auditoria de qualidade exige que o auditor em questão seja capaz, conjuntamente, de reconhecer e reportar distorções contábeis da entidade auditada (DeAngelo, 1981), assim, na ausência de ceticismo, a capacidade de reconhecimento das eventuais irregularidades contábeis pelo auditor é diretamente afetada.

Com isso, Olsen e Gold (2018) destacam que o ceticismo profissional tem recebido grande atenção em pesquisas acadêmicas. Por exemplo, Mubako e O’Donnell (2018) examinam se auditores que conhecem os diferentes riscos de fraude para cada tipo de conta tendem a se tornar menos céticos em relação às evidências. Os resultados do experimento indicaram que os auditores que sabiam que o risco de fraude era alto em termos de receita, mas baixo em termos de custos, classificaram como menor o risco de distorção contábil para contas de custos em relação aos auditores que tinham a informação de risco igual para ambas as contas.

Já Hussin, Saleh e Al-Smady (2019) analisam se fatores demográficos influenciam o nível de ceticismo dos auditores na Jordânia. Os resultados da pesquisa indicam que auditores que já haviam experenciado fraudes anteriormente estavam positivamente relacionados com atitudes de ceticismo, ao passo que o gênero dos auditores, o conhecimento específico e a experiência não apresentavam significância estatística na relação.

A pesquisa de Stevens, Moroney e Webster (2019), diante de um experimento, constata que quando a identidade da equipe é um fator importante, os auditores tendem a demonstrar um maior nível de ceticismo quando o parceiro de revisão apresenta um estilo favorável do que quando o estilo é não favorável.

Como visto, o ceticismo profissional ainda é um tema em voga em dias contemporâneos, cabendo ainda uma ampla gama de pesquisas acerca desse construto que é reportado como fundamental para os auditores tanto pelas pesquisas acadêmicas como pelos órgãos reguladores (Hurtt et al., 2013).

\subsection{Tríade Sombria de Personalidade (DarkTriad)}

Dentre as características aversivas de personalidade apontadas na literatura da psicologia, Paulhus e Williams (2002) destacam que três obtiveram destaque empírico: o maquiavelismo, o narcisismo e a psicopatia.

Estudos anteriores ao de Paulhus e Williams (2002) haviam sugerido relações entre o maquiavelismo e a psicopatia (Mchoskey; Worsel \& Szyarto, 1998), entre o narcisismo e a psicopatia (Gustafson \& Ritzer, 1995) e entre o maquiavelismo e o narcisismo (McHoskey, 1995). A partir dessas associações e da relevância dos referidos construtos para o cerne acadêmico, Paulhus e Williams (2002) investigam a relação de interdependência entre os três elementos com base em uma amostra de 245 estudantes de Psicologia e auferem ao final da pesquisa que tais elementos são parcialmente correlacionados, mas independentes entre si. Surge então a chamada "tríade sombria" (DarkTriad) de personalidade.

O maquiavelismo pode ser definido como um comportamento em que um determinado indivíduo manipula terceiros como instrumentos para atingir seus propósitos pessoais (Christie \& Geis, 1970; Wilson; Near \& Miller, 1996). Nelson e Gilbertson (1991) salientam que o termo maquiavelismo surge em uma menção aos trabalhos de Niccolò Machiavelli, em especial à obra "O Príncipe", e que esse autor viria a pagar um alto preço por seu reconhecimento. Isso porque o maquiavelismo foi cunhado por gerações subsequentes de escritores e estudantes como um sinônimo de ações imorais, comportamentos antiéticos e compromissos ocultos (Ralph, 1973). 
Para McIlwain (2003), o "sangue-frio" é uma das características marcantes dos maquiavelistas que, por sua vez, os permite manter a calma mesmo em cenários em que há intensa carga emocional. Essa frieza contribui para a manipulação de outros indivíduos e reporta uma tendência de ausência de empatia e sintonia afetiva com outras pessoas (Paal \& Bereczkei, 2007). Partindo desta premissa, seria factível crer que auditores que possuam traços de maquiavelismo possam apresentar maior nível de ceticismo que os demais em função da falta de conexão afetiva com terceiros (a exemplo dos gestores). Dessa forma, foi elaborada a seguinte hipótese:

- H1: O maquiavelismo influencia positivamente o ceticismo profissional de auditores independentes.

Em relação ao narcisismo - em sentido histórico -, o termo remonta à mitologia grega, em que o jovem Narciso, dotado de notável beleza, recusa o amor da igualmente bela e devotada Eco por acreditar que esta não estaria no mesmo patamar de sua perfeição. Então, Narciso inicia uma busca pela parceira perfeita, mas, diante de seu elevado ego, somente consegue se apaixonar por seu próprio reflexo, fato que o levaria à morte (Campbell \& Foster, 2002).

Salienta Pulver (1970) que na vasta literatura sobre o narcisismo só existem dois fatos unânimes: 1) que o conceito de narcisismo é um dos mais importantes no cerne da psicanálise; 2) que tal conceito é também um dos mais confusos. O autor destaca que essa confusão reside desde o início, quando mesmo Sigmund Freud (criador do termo), reportara alguma insatisfação com sua própria definição original de narcisismo, qual seja: "a atitude de uma pessoa que trata seu próprio corpo da mesma maneira que o corpo de um objeto sexual é normalmente tratado [...]" (Freud, 1914, p.73, apud Crockatt, 2006).

Desde o seminal trabalho de Freud (1914), o conceito de narcisismo foi ampliado e, em um dado momento, ocorreu a segregação entre as suas vertentes patológicas e não patológicas (Wallace \& Baumeister, 2002).

Esta seção se faz relevante, pois, embora algumas características sejam consideradas manifestaçõeschave de um narcisista, como a arrogância e o sentimento de direito (Rhodewalt \& Peterson, 2009; Pincus \& Lukowitsky, 2010), outras ainda apresentam dualidades de pensamento na literatura (Maxwell; Donnellan; Hopwood \& Ackerman, 2011), a exemplo da insegurança e da fragilidade emocional dos indivíduos narcisistas que, segundo Miller e Campbell (2008), estariam associadas ao narcisismo patológico, enquanto Rosenthal e Hooley (2010) discordam dessa lógica e argumentam o rotineiro equívoco nas mensurações do narcisismo como a resposta para tal crença.

Considerando que a DarkTriad é analisada sob a perspectiva não patológica não apenas do narcisismo, mas também dos demais construtos, conforme D’Souza e Lima (2018), a segunda hipótese de pesquisa foi delineada a partir de uma característica geral do narcisismo, a arrogância (Rhodewalt \& Peterson, 2009; Pincus \& Lukowitsky, 2010). Presume-se que auditores narcisistas, por acreditarem que são mais capazes em termos técnicos que quaisquer outros indivíduos, assumiriam um comportamento mais cético em relação aos reportes financeiros feitos por terceiros. Assim:

\section{- H2: $O$ narcisismo influencia positivamente o ceticismo profissional de auditores} independentes.

A psicopatia, por sua vez, se trata de um distúrbio de personalidade demarcado pela ausência de empatia, pelo egocentrismo, pela tomada de ações impulsivas e pela falta de remorso pelas consequências destes atos (Cleckley, 1976; Paulhus \& Williams, 2002; Jones \& Paulhus, 2014). 
Os psicopatas também podem se comportar antissocialmente de forma severa e premeditada, gerando consequências diretas na sociedade (Hare \& Neumann, 2008; Viding \& McCrory, 2018), contudo, esta não é uma característica geral desses indivíduos, segundo Viding e McCrory (2018). Corroboram esse argumento Jones e Paulhus (2014) ao explicarem que desde os trabalhos seminais que versam sobre a psicopatia, apenas dois elementos-chave foram delineados como típicos de um psicopata: o déficit sentimental e o déficit de autocontrole.

No contexto laboral, conforme Wexler (2008), psicopatas tendem a ser bem-sucedidos em função de habilidades como: frieza na tomada de decisões complexas, capacidade de realizar trabalhos árduos, confiança e objetividade. Estes atributos, de acordo com o autor, denotam confiança e lealdade junto aos colaterais de trabalho, gerando aos psicopatas uma grande rede de networking, usada para a obtenção de objetivos pessoais.

Nessa esteira, um auditor independente que apresente elevado nível de psicopatia (não clínica) deveria ser mais cético na conduta de seus serviços, dada a ausência de afeto com terceiros e o interesse em realizar um trabalho de alta qualidade visando à escalada hierárquica na empresa, ao reconhecimento de sua capacidade técnica perante os demais colaboradores e à promoção do próprio ego. Dessa forma, surge a terceira hipótese de pesquisa:

- H3: A psicopatia influencia positivamente o ceticismo profissional de auditores independentes.

Dadas as hipóteses previamente mencionadas, o desenho da presente pesquisa assume a forma reportada na Figura 1.

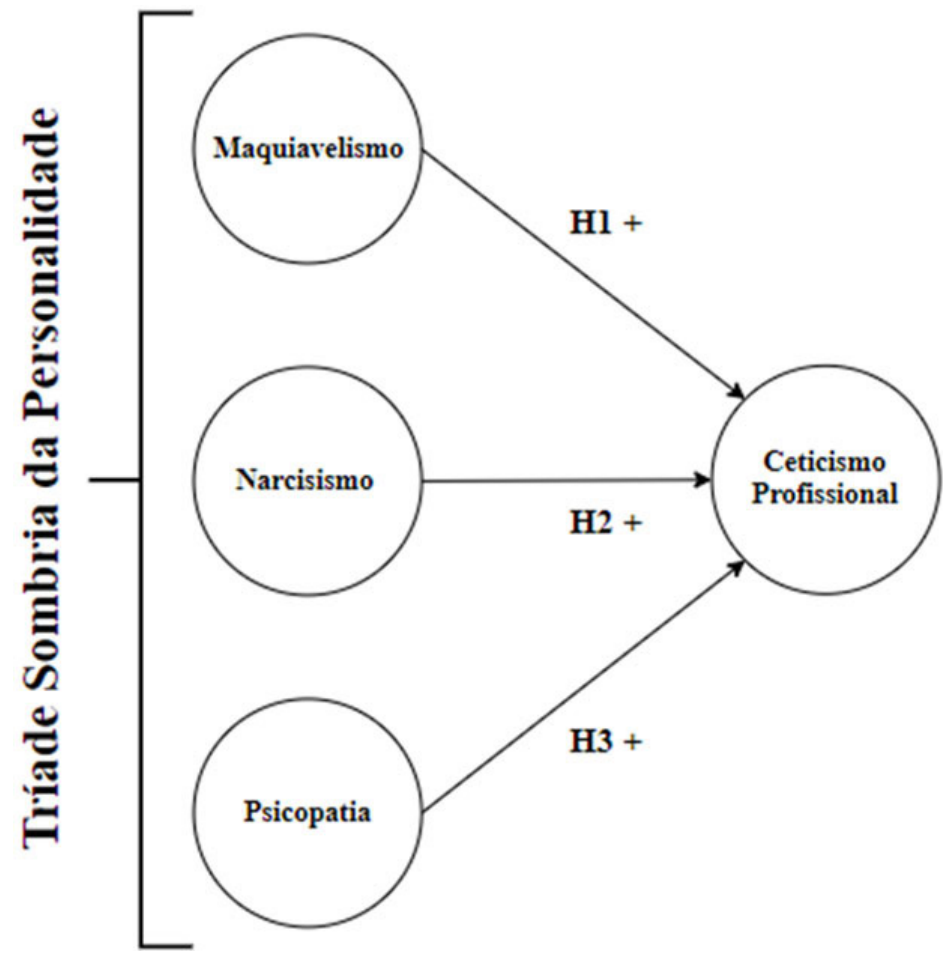

Figura 1. Desenho de pesquisa

Fonte: elaborado pelos autores (2020). 


\subsection{Estudos Anteriores}

$\mathrm{Na}$ literatura acadêmica é possível identificar uma gama de pesquisas (nacionais e internacionais) que relacionaram a tríade sombria da personalidade com a contabilidade. As esferas contábeis observadas em tais estudos são diversas (ambiente acadêmico; auditoria; contabilidade gerencial, etc.), reportando a compatibilidade e versatilidade do tema junto ao cerne contábil. Assim, em ordem cronológica, são apresentadas nesta subseção algumas das mais recentes pesquisas deste âmbito.

Majors (2016) realizou um experimento laboratorial com alunos de graduação que reportou evidências de que a exigência da divulgação de intervalos para as estimativas tende a gerar uma menor agressividade nos relatórios apresentados pelos gestores. Destaca a autora que este efeito é maximizado quando os gestores possuem um alto nível de ao menos um dos traços da DarkTriad. Isso seria explicado, a princípio, pelo efeito disciplinador das faixas obrigatórias diante desses indivíduos que, por natureza, sentem necessidade de controlar terceiros.

Em uma pesquisa sociobibliométrica, D'Souza e Jones (2017) buscaram caracterizar a pesquisa científica da DarkTriad nos contextos empresarial e contábil entre 2012 e 2014. A amostra do estudo (90 artigos) possibilitou aos autores a elaboração de uma taxonomia capaz de reportar as seguintes evidências: a) o maquiavelismo é o elemento que possui maior ênfase nas investigações acerca de manipulações; b) o narcisismo o elemento mais explorado, sendo rotineiramente associado à capacidade de liderança $\mathrm{e}$ às tomadas de decisões empresariais; e c) a psicopatia, via de regra, desperta o interesse acadêmico em se tratando de comportamentos hostis ou impróprios de líderes nas organizações. Os autores ressaltam ainda que, especificamente no cerne contábil, a maioria dos estudos associa a DarkTriad com a inclinação para a ocorrência de fraudes nos relatórios financeiros.

D'Souza e Lima (2018) analisam a influência da DarkTriad nos interesses profissionais almejados por estudantes de graduação em Ciências Contábeis. A pesquisa, que contou com 1.404 participantes de todas as regiões do Brasil, evidencia que a Auditoria e a Contabilidade em entidades privadas seriam os segmentos preferidos dos graduandos. De acordo com os resultados, os elementos da DarkTriad apresentam influência direta sobre todas as variáveis de interesse de carreira, sugerindo, de acordo com os autores, uma busca pelo prestígio social e pelo exibicionismo em função de posições hierárquicas elevadas.

Em uma pesquisa correlata, D'Souza e Lima (2019) averiguam a relação dos traços da DarkTriad com valores culturais de estudantes de Ciências Contábeis. Dentre os achados da pesquisa, destaca-se a tendência de valores individualistas para os respondentes que apresentavam altos níveis de personalidade sombria.

Já D’Souza et al. (2019) analisaram a relação entre a maximização de ganhos pessoais e empresariais e os traços da DarkTriad. A survey realizada com 263 gerentes indicou que, quando combinados os três elementos (narcisismo, maquiavelismo e psicopatia), os traços sombrios de personalidade apresentaram influência significativa e positiva na maximização de ganhos de forma oportunística.

Similarmente ao objetivo proposto para este estudo, Hobson et al. (2020), pressupõem que auditores independentes cujos traços sombrios de personalidade sejam elevados são menos propensos a confiar nos gerentes, reforçando o ceticismo profissional. O trabalho é do tipo experimental e os resultados corroboram a expectativa dos autores. Difere o referido estudo do aqui proposto em forma, metodologia e público-alvo, contudo, o propósito geral é o mesmo, ainda que no trabalho de Hobson et al. (2020) a perspectiva esteja sobre a "confiança injustificada" nos gestores, ao passo que no presente artigo tal perspectiva esteja diretamente ligada ao ceticismo profissional dos auditores independentes. 


\section{Metodologia}

Por buscar explicar um fenômeno (ceticismo profissional) diante de suas relações com os traços de personalidade sombrios dos auditores independentes, valendo-se de dados numéricos e de técnicas estatísticas, a metodologia desta pesquisa é caracterizada como quantitativa (Mujis, 2011).

A população do estudo contempla os auditores independentes com registro ativo no Cadastro Nacional de Auditores Independentes (CNAI). Em 4/2/2020, tal população montava a um total de 4.142 auditores. A plataforma Linkedin ${ }^{\oplus}$ foi utilizada como meio de contato com a população-alvo, sendo identificados 1.246 auditores independentes. Foi-lhes solicitado que respondessem a um questionário eletrônico, de forma voluntária, para que a pesquisa pudesse ser desenvolvida. Ao fim deste processo (28/4/2020), foram recebidas 170 respostas válidas, reportando, portanto, uma taxa de resposta de 13,6\% em relação ao grupo identificável.

Para mensurar de forma simples e eficaz a tríade sombria de personalidade dos indivíduos, Jones e Paulhus (2014) criaram a Short DarkTriad (SD3). Posteriormente, as 27 assertivas deste instrumento (9 para cada um dos 3 traços) foram traduzidas por D'Souza e Lima (2018), sendo mantida a estrutura original de uma escala Likert de 7 pontos. Por ser um instrumento validado que atende especificamente ao propósito desta pesquisa, a versão traduzida de D’Souza e Lima (2018) foi assumida como a responsável para a métrica do maquiavelismo, do narcisismo e da psicopatia.

Já para o ceticismo profissional, o instrumento valeu-se da escala proposta por Hurtt (2010), que mensura o ceticismo dos auditores independentes a partir de 30 itens originalmente intervalados em respostas que variam de 1 a 6 . Os itens dessa escala são segregados em 6 diferentes subgrupos, quais sejam: Mente Questionadora (MQ); Suspensão do Julgamento (SJULG); Busca de Conhecimento (BC); Compreensão Interpessoal (CINT); Autoestima (AEST); e Autonomia (AUT). Para esta pesquisa foi adotada a tradução da escala de Hurtt (2010) feita por Haveroth e Cunha (2018) e, visando igualar os itens para mitigar possíveis vieses de escala, foi adotada para este construto, também, uma escala de 7 pontos.

Cabe destacar que seja para a SD3, seja para o ceticismo profissional, foram mantidas as questões reversas dispostas pelos autores originais. E, para ambos os casos, a consistência interna do instrumento foi mensurada pelo Alfa de Cronbach (Maroco\&Garcia-Marques, 2006).

Outros questionamentos foram feitos com o propósito de elencar variáveis de controle para o modelo. Eles remetem ao tempo de experiência na função de auditor (Nelson, 2009; Hurtt et al., 2013), sendo tal variável mensurada em anos completos na função; ao gênero do(a) auditor(a) (Bobek; Hageman\&Radtke, 2015), trabalhada neste artigo em forma dicotômica (Masculino = 1; Feminino = 0); e ao fato de exercerem suas funções, ou não, em uma das Big 4, conforme DeAngelo (1981), igualmente considerada de forma dicotômica (Big $4=1$; Demais casos $=0$ ). Ainda, apenas para fins descritivos, foi questionado aos respondentes o estado ao qual tinham vinculados seus respectivos registros no CNAI.

Para a obtenção dos 3 elementos da DarkTriad - aquiavelismo, narcisismo e psicopatia, doravante abreviados por MAQ, NAR e PSI - a partir da SD3, e também das variáveis MQ, SJULG, BC, CINT, AEST e AUT, derivadas do ceticismo profissional de Hurtt (2010), foram geradas variáveis latentes em função de análises fatoriais confirmatórias, dado o intuito de corroborar uma concepção teórica já fundamentada previamente (Fávero; Belfiore; Silva \& Chan, 2009).

Por serem tais construtos dispostos em escalas ordinais, a base da análise fatorial confirmatória foi tomada a partir de matrizes de correlações policóricas, corroborando a sugestão metodológica feita por Holgado-Tello, Chacón-Moscoso, Barbero-García e Vila-Abad(2010). Bistaffa (2010) exalta que uma matriz de correlação policórica é formada diante da associação bivariada de duas variáveis ordinais com no mínimo 3 categorias. Nesse sentido, segundo o autor, a partir de hipotéticas variáveis categóricas A e B e suas respectivas variáveis latentes $\mathrm{X}$ e $\mathrm{Y}$, havendo relação entre tais variáveis e considerando que: $A=a_{i}$, se $\lambda_{i-1} \leq \mathrm{X}<\lambda_{i-1} ; i=1,2, \ldots, m$ e $\mathrm{B}=\mathrm{b}_{\mathrm{i}}$, se $\tau_{j-1} \leq \mathrm{Y}<\tau_{j} ; j=1,2, \ldots, n$, diante dos limiares $\tau_{i}$ e $\lambda_{j}$, sendo $\lambda_{0}=\tau_{0}=-\infty$ e $\lambda_{m}=\tau_{n}=+\infty$, surge o coeficiente de correlação policórica $\rho$, designado como a relação produto-momento entre as variáveis latentes $\mathrm{X}$ e $\mathrm{Y}$. 
O método adotado para a extração das variáveis latentes foi a análise dos componentes principais, uma vez que o propósito inicial era reduzir as variáveis originais em um menor número (Fávero et al., 2009). Ainda nesse processo, foi adotado o critério a priori durante a extração dos fatores considerando apenas uma unidade para cada grupo.

Finalizada a extração das variáveis latentes por meio da análise fatorial, foram geradas seis equações a serem regredidas via Mínimos Quadrados Ordinários (MQO), destacadas a seguir:

$$
\begin{gathered}
\mathrm{MQ}=\alpha+\beta_{1} \mathrm{GEN}+\beta_{2} \mathrm{BIG} 4+\beta_{3} \mathrm{EXP}+\beta_{4} \mathrm{MAQ}+\beta_{5} \mathrm{NAR}+\beta_{6} \mathrm{PSI}+\varepsilon \\
\mathrm{SJULG}=\alpha+\beta_{1} \mathrm{GEN}+\beta_{2} \mathrm{BIG}+\beta_{3} \mathrm{EXP}+\beta_{4} \mathrm{MAQ}+\beta_{5} \mathrm{NAR}+\beta_{6} \mathrm{PSI}+\varepsilon \\
\mathrm{BC}=\alpha+\beta_{1} \mathrm{GEN}+\beta_{2} \mathrm{BIG}+\beta_{3} \mathrm{EXP}+\beta_{4} \mathrm{MAQ}+\beta_{5} \mathrm{NAR}+\beta_{6} \mathrm{PSI}+\varepsilon \\
\mathrm{CINT}=\alpha+\beta_{1} \mathrm{GEN}+\beta_{2} \mathrm{BIG} 4+\beta_{3} \mathrm{EXP}+\beta_{4} \mathrm{MAQ}+\beta_{5} \mathrm{NAR}+\beta_{6} \mathrm{PSI}+\varepsilon \\
\mathrm{AEST}=\alpha+\beta_{1} \mathrm{GEN}+\beta_{2} \mathrm{BIG} 4+\beta_{3} \mathrm{EXP}+\beta_{4} \mathrm{MAQ}+\beta_{5} \mathrm{NAR}+\beta_{6} \mathrm{PSI}+\varepsilon \\
\mathrm{AUT}=\alpha+\beta_{1} \mathrm{GEN}+\beta_{2} \mathrm{BIG}+\beta_{3} \mathrm{EXP}+\beta_{4} \mathrm{MAQ}+\beta_{5} \mathrm{NAR}+\beta_{6} \mathrm{PSI}+\varepsilon
\end{gathered}
$$

Foram realizados os testes de Jarque-Bera e de Breusch-Pagan para a verificação da normalidade e da homocedasticidade dos resíduos, de acordo com Fávero et al. (2009). Na ausência de tendência Gaussiana para o comportamento dos resíduos, foi assumido o relaxamento do pressuposto com base no Teorema do Limite Central (Gujarati \& Porter, 2011), ao passo que a heterocedasticia foi tratada, quando existente, diante da correção robusta de White (Fávero et al., 2009). Não obstante, foi considerada como limite aceitável de multicolinearidade entre os regressores a marca de 10 unidades no Fator de Inflação da Variância (FIV), conforme Gujarati e Porter (2011).

Por fim, visando trazer robustez aos resultados da pesquisa, foram realizadas regressões estimadas por Mínimos Desvios Absolutos (MDA) para os modelos previamente relatados. Conforme Ohlson e Kim (2015), esta forma de estimação, ao substituir a média pela mediana como parâmetro, sugere maior confiança nos resultados perante a influência de eventuais outliers. É mister ressaltar também que esta técnica, adotada na presente pesquisa como medida de sensibilidade, é do tipo semi-paramétrica, sendo isenta, portanto, da necessidade de assunções prévias de parâmetros como a normalidade e a homocedasticidade dos resíduos (Duarte, Girão \& Paulo, 2017).

Para fins elucidativos, os modelos MDA dar-se-ão por:

$$
\mathrm{Q} \tau(\mathrm{VD} \mid \mathrm{x})=\alpha(\tau)+\beta 1(\tau) \mathrm{GEN}+\beta 2(\tau) \mathrm{BIG} 4+\beta 3(\tau) \mathrm{EXP}+\beta 4(\tau) \mathrm{MAQ}+\beta 5(\tau) \mathrm{NAR}+\beta 6(\tau) \mathrm{PSI}+\varepsilon
$$

- Em que: Q é a função quantil condicional; VD são as Variáveis Dependentes das equações 1 a 6; $\tau$ é o quantil-parâmetro da regressão, representado pela mediana $(0,5)$; $\mathrm{x}$ é a matriz de regressores; $\alpha$ é o intercepto; $\beta_{1,2,3 \ldots \mathrm{n}}$ são os coeficientes angulares; $\varepsilon$ é o termo de erro estocástico. 


\section{Análise e Discussão dos Resultados}

\subsection{Validação do Instrumento de Pesquisa e Caracterização da Amostra}

Em primeira instância desta seção, faz-se pertinente relatar que os construtos da pesquisa, quais sejam, a SD3 e o ceticismo de Hurtt (2010), apresentaram fiabilidade interna adequada. Isso porque seus respectivos a de Cronbach foram 0,8182 e 0,8457. Assim, assumindo os preceitos de Murphy e Davidshofer (2005), estes elementos estariam enquadrados na faixa de fiabilidade "moderada a elevada". Ademais, salientam Nunnally e Bernstein (1994) que no âmbito das ciências sociais (caso da presente pesquisa), valores entre 0,7 e 0,8 já seriam aceitáveis para validar o instrumento quanto à sua consistência interna. $\mathrm{O}$ mesmo procedimento foi tomado considerando os constructos individualmente e apenas dois destes obtiveram valores inferiores a $0,7(\mathrm{NAR}=0,6454$ e $\mathrm{MQ}=0,6888)$. Ou seja, ainda que considerados de forma isolada, os resultados indicam consistência adequada diante de uma medida de tolerância.

Quanto à caracterização dos respondentes, tem-se que $51(\cong 29,82 \%)$ destes se declararam como do gênero feminino, ao passo que $119(\cong 69,59 \%)$ o fizeram no gênero masculino. Esta predominância do gênero masculino frente ao feminino no escopo das firmas de auditoria também foi identificada nas pesquisas de Mendes et al. (2018) e Haveroth e Cunha (2018), porém, com diferentes percentuais de maioria masculina, $86,67 \%$ e $74,90 \%$, respectivamente. Assim, os resultados da presente pesquisa e de suas recentes correlatas sugerem indícios de que o cerne da auditoria independente seja dominado por indivíduos masculinos.

Os respondentes puderam ser segregados também em relação ao tamanho da firma em que atuavam (Big 4 x Não Big 4). Nesse sentido, 101 participantes se enquadraram no grupo Não Big 4, ou seja, cerca de $59 \%$ da amostra. Consequentemente, 69 respondentes (cerca de $41 \%$ da amostra) declararam pertencer ao quadro de funcionários de uma das quatro maiores empresas de auditoria independente do mundo. A pesquisa de Haveroth e Cunha (2018), que também se valeu da plataforma Linkedin ${ }^{\circledR}$ para acesso aos auditores independentes cadastrados no CNAI, obteve um percentual de aproximadamente $49 \%$ para o grupo Big 4 considerando um total de 255 participantes. Então, a princípio, os números percebidos nesta questão da pesquisa se aproximam do referido estudo, não denotando, aparentemente, qualquer tipo de viés em função de variabilidade amostral.

Ainda, tem-se a composição amostral diante do fator geográfico (UF ao qual o auditor independente possui seu vínculo junto ao CNAI), visualizada a partir da Tabela 1, a seguir. 
Tabela 1

Composição amostral (geográfica)

\begin{tabular}{|c|c|c|c|c|c|}
\hline Região & FA & FR (aprox.) & UF & FA & FR (aprox.) \\
\hline \multirow{4}{*}{ Centro-Oeste } & \multirow{4}{*}{9} & \multirow{4}{*}{$5,294 \%$} & Distrito Federal (DF) & 4 & $2,353 \%$ \\
\hline & & & Goiás (GO) & 2 & $1,176 \%$ \\
\hline & & & Mato Grosso (MT) & 2 & $1,176 \%$ \\
\hline & & & Mato Grosso do Sul (MS) & 1 & $0,059 \%$ \\
\hline \multirow{3}{*}{ Nordeste } & \multirow{3}{*}{8} & \multirow{3}{*}{$4,705 \%$} & Bahia (BA) & 4 & $2,353 \%$ \\
\hline & & & Ceará (CE) & 1 & $0,059 \%$ \\
\hline & & & Pernambuco (PE) & 3 & $1,177 \%$ \\
\hline \multirow{4}{*}{ Sudeste } & \multirow{4}{*}{78} & \multirow{4}{*}{$45,882 \%$} & Espírito Santo (ES) & 2 & $1,176 \%$ \\
\hline & & & Minas Gerais (MG) & 6 & $3,529 \%$ \\
\hline & & & Rio de Janeiro (RJ) & 4 & $2,353 \%$ \\
\hline & & & São Paulo (SP) & 66 & $38,823 \%$ \\
\hline \multirow{3}{*}{ Sul } & \multirow{3}{*}{75} & \multirow{3}{*}{$44,117 \%$} & Paraná (PR) & 27 & $15,882 \%$ \\
\hline & & & Rio Grande do Sul (RS) & 28 & $16,470 \%$ \\
\hline & & & Santa Catarina (SC) & 20 & $11,765 \%$ \\
\hline TOTAL & 170 & $100 \%$ & - & 170 & $100 \%$ \\
\hline
\end{tabular}

Nota: FA = Frequência Absoluta; FR = Frequência Relativa; UF = Unidade Federativa.

Fonte: dados da pesquisa (2020).

Perante os dados da Tabela 1, é possível notar uma predominância das regiões Sudeste e Sul, sendo o Estado de São Paulo o mais representado na pesquisa. Esses números seguem a proporção populacional da pesquisa (auditores com CNAI ativo), em que as regiões Sudeste e Sul são as que possuem o maior número de auditores e São Paulo é a UF que lidera tal quesito. Isso sugere ausência de enviesamento por variabilidade amostral nesta questão, a priori.

Não obstante, tanto a liderança de SP, no quantitativo amostral entre os estados, como a liderança da região Sudeste (seguida pela região Sul) entre as regiões também foram percebidas na pesquisa de Haveroth e Cunha (2018).

\subsection{Análise fatorial e Estatísticas Descritivas}

Com base nas matrizes de correlações policóricas, foram realizadas as análises fatoriais para extração das variáveis latentes MAQ, NAR e PSI (SD3) e MQ, SJULG, BC, CINT, AEST e AUT (ceticismo profissional). A Tabela 2 apresenta um resumo deste processo. 
Tabela 2

\section{Análise fatorial}

\begin{tabular}{|c|c|c|c|}
\hline Variável & Teste de Bartlett & KMO & Comunalidade \\
\hline AEST & 0,000 & 0,8566 & 0,7800 \\
\hline AUT & 0,000 & 0,8102 & 0,7622 \\
\hline BC & 0,000 & 0,8646 & 0,8614 \\
\hline CINT & 0,000 & 0,8128 & 0,7291 \\
\hline MAQ & 0,000 & 0,7279 & 0,4789 \\
\hline MQ & 0,000 & 0,7964 & 0,6289 \\
\hline NAR & 0,000 & 0,6619 & 0,4469 \\
\hline PSI & 0,000 & 0,8217 & 0,6028 \\
\hline SJULG & 0,000 & 0,8238 & 0,7080 \\
\hline
\end{tabular}

Nota: $\mathrm{KMO}=$ Kayser-Meyer-Olkin.

Fonte: dados da pesquisa (2020).

De acordo com Fávero et al. (2009), para uma adequada análise fatorial é exigida a rejeição da hipótese nula do teste de esfericidade de Bartlett, ou seja, é necessário que a matriz de correlação não seja uma matriz identidade. Os p-valores de todas as variáveis para tal teste, conforme Tabela 2, indicam o aceite da premissa considerando um nível de confiança de $99 \%$.

O critério de Kayser-Meyer-Olkin (KMO), que verifica a consistência geral dos dados, também apresentou valores fiáveis para a continuidade da análise fatorial. Isso porque, de acordo com Fávero et al. (2009), medidas de KMO superiores a 0,6 já seriam consideradas adequadas, fato confirmado nos dados da pesquisa. Considerando o tamanho da amostra $(n=170)$, as comunalidades dos fatores também podem ser consideradas como estatisticamente significativas para este estudo, segundo Hair, Anderson, Tatham e Black (2005).

Como medida de análise complementar, o critério de extração de fatores a priori foi substituído pelo critério da raiz latente (critério de Kaiser) e todos os resultados iniciais foram mantidos, uma vez que, para todas as variáveis, apenas um fator apresentou autovalor (eigenvalue) superior a uma unidade (Fávero et al., 2009).

Isto posto, tem-se a partir da Tabela 3 a sumarização das variáveis quantitativas da pesquisa em caráter descritivo.

Tabela 3

\section{Estatísticas descritivas}

\begin{tabular}{lccccc}
\hline \multicolumn{1}{c}{ Variável } & Média & Mediana & Desvio-Padrão & Mínimo & Máximo \\
\hline AEST & 6,13 & 6,27 & 1,13 & 1,25 & 7,40 \\
\hline AUT & 6,31 & 6,42 & 1,13 & 2,26 & 7,79 \\
\hline BC & 6,94 & 7,31 & 0,70 & 1,65 & 7,40 \\
\hline CINT & 6,00 & 6,21 & 1,36 & 1,59 & 7,78 \\
\hline EXP & 8,98 & 7,00 & 7,86 & 0,00 & 37,00 \\
\hline MAQ & 4,61 & 4,53 & 1,48 & 1,38 & 8,62 \\
\hline MQ & 6,95 & 6,96 & 0,83 & 3,93 & 8,12 \\
\hline NAR & 5,73 & 5,62 & 1,41 & 2,53 & 10,21 \\
\hline PSI & 2,53 & 2,18 & 1,11 & 1,29 & 8,53 \\
\hline SJULG & 6,50 & 6,59 & 0,99 & 3,36 & 7,84 \\
\hline
\end{tabular}

Fonte: dados da pesquisa (2020). 
Em relação às variáveis que possuem propriedades métricas, nota-se um baixo nível de dispersão, salvo a única variável discreta (EXP). Este fato, corroborado pela proximidade entre as médias e medianas, indica pouca influência de outliers no conjunto amostral.

\subsection{Análise das Regressões (MQO)}

A Tabela 4 denota os resultados dos testes para verificação de pressupostos básicos a serem assumidos nas análises de regressões estimadas por MQO.

Tabela 4

Pressupostos para as regressões

\begin{tabular}{ccccc}
\hline \multicolumn{7}{c}{ Painel A - Normalidade e Homocedasticidade dos Resíduos } \\
\hline \multirow{2}{*}{ Equação } & \multicolumn{2}{c}{ Jarque-Bera } & \multicolumn{2}{c}{ Breusch-Pagan } \\
\cline { 2 - 5 } & \multicolumn{1}{c}{ Chi $^{2}$} & p-valor & Chi $^{2}$ & p-valor \\
\hline 1 & 7,59 & 0,022 & 3,58 & 0,058 \\
\hline 2 & 12,52 & 0,002 & 1,62 & 0,203 \\
\hline 3 & 594,50 & 0,000 & 141,01 & 0,000 \\
\hline 4 & 14,13 & 0,000 & 0,41 & 0,520 \\
\hline 5 & 81,32 & 0,000 & 10,16 & 0,001 \\
\hline 6 & 14,04 & 0,000 & 15,43 & 0,000 \\
\hline VIF & Painel B - MulticolinearidadeentreRegressores & & PSI \\
\hline
\end{tabular}

Nota: VIF = Variance Inflation Factor.

Fonte: dados da pesquisa (2020).

Assumindo um nível de confiança de 95\%, os dados da Tabela 4, no Painel A, indicam ausência de comportamento Gaussiano para os resíduos em todas as equações propostas. Mas, diante do tamanho da amostra deste estudo $(\mathrm{n}=170)$ e em respeito ao Teorema do Limite Central, este pressuposto pôde ser relaxado (Gujarati\& Porter, 2011). O painel A aponta ainda a existência de problemas de heterocedasticidade nas equações 3, 5 e 6 perante o nível de significância proposto. Para solucionar estes entraves, foi adotada a correção de White nas referidas equações, tornando seus erros-padrão robustos.

Por fim, no Painel B, podem ser identificados valores muito abaixo do limite disposto por Gujarati e Porter (2011) para os VIF's, indicando, a princípio, ausência de problemas derivados de colinearidade entre as variáveis de estímulo.

Assim, faz-se pertinente a análise das regressões elencadas na seção que trata da metodologia. Este resumo é dado na Tabela 5, a seguir. 
Tabela 5

Regressões MQO

\begin{tabular}{|c|c|c|c|c|c|c|c|}
\hline \multicolumn{8}{|c|}{ Painel A } \\
\hline $\begin{array}{c}\text { Equação / } \\
\text { Regressando }\end{array}$ & $a$ & GEN & BIG4 & EXP & MAQ & NAR & PSI \\
\hline $\begin{array}{l}(1) \\
\mathrm{MQ}\end{array}$ & $\begin{array}{c}6,408^{* * *} \\
(21,58)\end{array}$ & $\begin{array}{l}0,015 \\
(0,10)\end{array}$ & $\begin{array}{l}-0,049 \\
(-0,37)\end{array}$ & $\begin{array}{c}0,022^{* *} \\
(2,57)\end{array}$ & $\begin{array}{l}-0,040 \\
(-0,74)\end{array}$ & $\begin{array}{c}0,113^{* *} \\
(2,26)\end{array}$ & $\begin{array}{l}-0,401 \\
(-0,56)\end{array}$ \\
\hline $\begin{array}{c}(2) \\
\text { SJULG }\end{array}$ & $\begin{array}{c}6,857 * * * \\
(19,31)\end{array}$ & $\begin{array}{l}-0,161 \\
(-0,94)\end{array}$ & $\begin{array}{l}-0,207 \\
(-1,29)\end{array}$ & $\begin{array}{l}0,007 \\
(0,70)\end{array}$ & $\begin{array}{l}0,027 \\
(0,41)\end{array}$ & $\begin{array}{l}0,018 \\
(0,29)\end{array}$ & $\begin{array}{c}-0,184^{* *} \\
(-2,12)\end{array}$ \\
\hline $\begin{array}{l}\text { (3) } \\
\mathrm{BC}\end{array}$ & $\begin{array}{c}7,276 * \star \star \\
(31,94)\end{array}$ & $\begin{array}{l}0,059 \\
(0,52)\end{array}$ & $\begin{array}{l}-0,142 \\
(-1,34)\end{array}$ & $\begin{array}{l}0,007 \\
(0,91)\end{array}$ & $\begin{array}{l}0,009 \\
(0,22)\end{array}$ & $\begin{array}{l}0,029 \\
(0,89)\end{array}$ & $\begin{array}{l}-0,233 \\
(-1,58)\end{array}$ \\
\hline $\begin{array}{l}\text { (4) } \\
\text { CINT }\end{array}$ & $\begin{array}{c}5,645^{\star * *} \\
(11,59)\end{array}$ & $\begin{array}{l}-0,345 \\
(-1,46)\end{array}$ & $\begin{array}{l}0,281 \\
(1,28)\end{array}$ & $\begin{array}{l}-0,008 \\
(-0,59)\end{array}$ & $\begin{array}{l}0,030 \\
(0,33)\end{array}$ & $\begin{array}{l}0,140 * \\
(1,70)\end{array}$ & $\begin{array}{l}-0,148 \\
(-1,26)\end{array}$ \\
\hline $\begin{array}{c}(5) \\
\text { AEST }\end{array}$ & $\begin{array}{c}5,012^{\star \star *} \\
(13,18)\end{array}$ & $\begin{array}{l}0,245 \\
(1,27)\end{array}$ & $\begin{array}{c}-0,443^{* *} \\
(-2,52)\end{array}$ & $\begin{array}{c}0,031 * * * \\
(2,94)\end{array}$ & $\begin{array}{l}0,050 \\
(0,51)\end{array}$ & $\begin{array}{c}0,259 * * * \\
(4,05)\end{array}$ & $\begin{array}{c}-0,340 * * * \\
(-3,32)\end{array}$ \\
\hline $\begin{array}{l}(6) \\
\text { AUT }\end{array}$ & $\begin{array}{c}6,456 * * * \\
(14,26)\end{array}$ & $\begin{array}{c}0,579 * * * \\
(2,96)\end{array}$ & $\begin{array}{l}-0,027 \\
(-0,15)\end{array}$ & $\begin{array}{l}0,001 \\
(0,09)\end{array}$ & $\begin{array}{c}-0,140^{*} \\
(-1,82)\end{array}$ & $\begin{array}{l}0,091 \\
(1,50)\end{array}$ & $\begin{array}{l}-0,170 \\
(-1,29)\end{array}$ \\
\hline \multicolumn{8}{|c|}{ Painel B } \\
\hline $\begin{array}{c}\text { Equação / } \\
\text { Regressando }\end{array}$ & & $F$ & & Prob $>F$ & & & \\
\hline (1) MQ & & 2,24 & & 0,0417 & & & \\
\hline (2) SJULG & & 1,46 & & 0,1942 & & & \\
\hline (3) BC & & 1,38 & & 0,2257 & & & \\
\hline (4) CINT & & 1,69 & & 0,1271 & & & \\
\hline (5) AEST & & 7,16 & & 0,0000 & & & \\
\hline (6) AUT & & 3,39 & & 0,0036 & & & \\
\hline
\end{tabular}

Nota: * = Nível de confiança de 90\%; ** = Nível de confiança de 95\%; *** = Nível de confiança de 99\%.

Fonte: dados da pesquisa (2020).

Com base nos dados expostos na Tabela 5, é possível, de antemão, desconsiderar quaisquer relações lineares entre os regressores das equações 2, 3 e 4 e seus respectivos regressandos. Isso porque, ao observar o Painel B, nota-se que tais equações apresentam p-valores $(F)>0,05$, ou seja, os modelos, em si, não são estatisticamente significativos diante do nível de confiança proposto (95\%).

Já as equações 1, 5 e 6 - estatisticamente significantes e com poderes de explicação $\left(\mathrm{R}^{2}\right)$ de cerca de $7 \%, 23 \%$ e $10 \%$, respectivamente -, apresentam resultados distintos. A variável de controle GEN, por exemplo, só é estatisticamente significativa para a característica de Autonomia. Aparentemente, indivíduos do sexo masculino tendem a apresentar traços mais fortes dessa característica quando comparados aos indivíduos do sexo feminino. Este resultado contraria aquele obtido por Haveroth e Cunha (2018), quando estes autores (a partir de estatísticas descritivas) perceberam médias de pontuação muito aproximadas entre esses grupos. Uma possível explicação para tal discrepância seja a diferença nos métodos utilizados para cada pesquisa, não sendo descartado, porém, o eventual impacto decorrente de variabilidade amostral. 
BIG4, outra variável de controle, é significativa em termos estatísticos apenas para AEST. O sinal negativo encontrado sugere que auditores independentes que atuem por alguma das Big Four tenham autoestima menor que seus colegas de profissão das demais firmas de auditoria, contrariando a aparente indiferença deste aspecto encontrada por Haveroth e Cunha (2018). Hurtt (2010) explicou que a autoestima corresponde ao nível em que os auditores confiam em si mesmos. Assim, este resultado iria de encontro ao exposto de DeAngelo (1981), ainda que parcialmente, no tocante à maior qualidade dos serviços prestados por grandes firmas de auditoria. Cabe destacar, contudo, que embora a confiança seja relevante para a formação do ceticismo profissional dos auditores, o excesso de confiança é tido como um problema rotineiro perante os profissionais desse cerne (Lucena, Fernandes \& Silva, 2011), prejudicando, eventualmente, a qualidade dos serviços prestados (Steppan, Santiago, Silva, Cavalcante \& Silva, 2015).

A última variável de controle (EXP) mostrou-se estatisticamente significativa perante MQ e AEST. Em ambos os casos o sinal reportado foi positivo, sugerindo que auditores mais experientes sejam mais questionadores e possuam maior autoestima e confiança quanto às suas próprias capacidades. Tal resultado está em linha com as pesquisas de Nelson (2009) e Hurtt et al. (2013), considerando que a experiência traz consigo uma maior capacidade de identificar padrões, erros, etc. Todavia, assim como foi explicado anteriormente, Nelson (2009) ressalta que auditores mais experientes também podem vir a mitigar o ceticismo profissional quando assumem posturas pouco prudentes a partir de seus vícios laborais.

Ao analisar as variáveis de interesse da pesquisa, é possível notar que a variável MAQ somente é estatisticamente significativa (considerando um nível de 10\% de significância) para o construto que se refere à autonomia dos auditores independentes. $\mathrm{O}$ sinal negativo que precede esse coeficiente indica uma relação inversa entre as variáveis, denotando uma menor autonomia dos auditores independentes que apresentam características de maquiavelismo.

O referido resultado contraria aquilo que era esperado na pesquisa, já que indivíduos maquiavélicos não possuem laços afetivos com terceiros (Paal \& Bereczkei, 2007) e, assim, deveriam agir de forma completamente autônoma, desconsiderando a opinião alheia para a assunção do nível de evidência exigido para uma dada hipótese (Hurtt, 2010). Talvez esse controverso resultado possa estar conectado ao fato de que seres maquiavélicos manipulam terceiros em prol de fins próprios (Christie \& Geis, 1970; Wilson et al., 1996) e, dessa forma, a menor autonomia poderia ser interpretada, na verdade, como uma delegação de tarefas as quais o auditor não deseje realizar. Mais estudos são necessários sobre este item para melhor compreender o presente achado de pesquisa.

Quanto ao narcisismo (NAR), depreende-se uma relação linear estatisticamente significativa desta variável diante de indicativos de mentes questionadoras e autoestima. Ambos os resultados estão em linha com a ideia de que indivíduos narcisistas são arrogantes (Rhodewalt \& Peterson, 2009; Pincus \& Lukowitsky, 2010). Com isso, auditores que apresentam esta característica, conforme esperado pela pesquisa e indicado diante dos resultados, devem ser mais questionadores por duvidarem da capacidade de outrem no processo de validação de uma determinada questão e, paralelamente, devem também apresentar elevada confiança em suas próprias capacidades.

A variável NAR, contudo, não se fez estatisticamente significante diante da característica de autonomia (AUT). Este resultado foge daquilo que era esperado, mas é possivelmente explicado pela eventual falta de poder para a tomada de decisões autônomas pelos auditores independentes em suas firmas. Esta explanação parece factível por ser de cerca de 9 anos a média de experiência dos auditores independentes da amostra. Assim, é possível que parte considerável da amostra seja composta de auditores que ainda não ocupem postos de gerência, e, por conseguinte, estejam impossibilitados de agir por conta própria em muitos casos (Muzel, 2018). 
E, em relação ao traço de psicopatia (PSI), nota-se que tal variável só foi estatisticamente significante perante a variável AEST. Na referida relação, o sinal negativo indica que auditores com elevados níveis de psicopatia teriam inclinação a uma menor autoestima. Este resultado contraria a sugestão de Wexler (2008) de que indivíduos psicopatas teriam a confiança como um traço típico em suas atividades laborais. Talvez este seja um ponto específico da função dos auditores, sendo necessárias futuras investigações comparativas para averiguar essa questão.

Chama a atenção, também, a não significância estatística de PSI diante de AUT. Isso porque o egocentrismo é um ponto característico dos psicopatas (Paulhus \& Williams, 2002; Jones \& Paulhus, 2014) e, portanto, um sinal positivo para a variável de autonomia era esperado nessa relação. Esta questão pode ser explicada diante de possíveis relações de poder nas firmas de auditoria que extrapolam a mera perspectiva individual dos respondentes, sendo tal condição exequível diante dos argumentos elencados previamente quanto à variável NAR, quais sejam: o tempo médio de experiência dos participantes da pesquisa e a consequente atuação em cargos não gerenciais, que os impossibilita de agirem por conta própria em diversas situações, conforme Muzel (2018).

Em suma, o conjunto de resultados indica a rejeição total de $\mathrm{H} 1$ e $\mathrm{H} 3$, ao passo que a $\mathrm{H} 2$ foi rejeitada apenas parcialmente.

\subsection{Análise de sensibilidade (MDA)}

Conforme descrito na seção de procedimentos metodológicos, são apresentados, na sequência, os resultados das regressões estimadas por mínimos desvios absolutos como forma de análise de sensibilidade dos resultados gerais. A Tabela 6 reporta os dados que se referem as equações 1, 5 e 6 , apenas, de forma a possibilitar comparações em relação aos modelos válidos estimados por MQO.

Tabela 6

\section{Regressões MDA}

\begin{tabular}{cccccccc}
\hline $\begin{array}{c}\text { Equação / } \\
\text { Regressando }\end{array}$ & $\mathbf{a}$ & GEN & BIG4 & EXP & MAQ & NAR & PSI \\
\hline$(1)$ & $6,568^{* * *}$ & 0,003 & $-0,125$ & $0,026 * *$ & $-0,107$ & $0,111^{*}$ & 0,057 \\
MQ & $(18,03)$ & $(0,02)$ & $(-0,75)$ & $(2,58)$ & $(-1,58)$ & $(1,85)$ & $(0,64)$ \\
\hline$(5)$ & $5,106^{* * *}$ & $0,386 * *$ & $-0,502 * * *$ & $0,034 * * *$ & $-0,033$ & $0,309 * * *$ & $-0,320 * * *$ \\
AEST & $(13,43)$ & $(2,11)$ & $(-2,95)$ & $(3,26)$ & $(0,47)$ & $(4,76)$ & $(-3,50)$ \\
\hline$(6)$ & $6,053^{* * *}$ & 0,439 & $-0,134$ & 0,001 & $-0,136$ & 0,184 & $-0,135$ \\
AUT & $(9,12)$ & $(1,36)$ & $(-0,44)$ & $(0,07)$ & $(-1,12)$ & $(1,63)$ & $(-0,83)$ \\
\hline
\end{tabular}

Nota: * = Nível de confiança de 90\%; ** = Nível de confiança de 95\%; *** = Nível de confiança de 99\%.

Fonte: dados da pesquisa (2020).

Entre as variáveis de controle, tem-se apenas uma alteração em relação aos resultados iniciais. Ela remete à variável GEN, que passa a ser estatisticamente significativa diante da variável AEST (95\% de confiança), mas que, em contrapartida, perde essa significância estatística na relação com a variável AUT.

Já as variáveis BIG4 e EXP mantêm todas as suas relações de significância estatística. Os coeficientes estimados por MDA são muito próximos aos coeficientes estimados por MQO e seus sinais não foram modificados.

Para as variáveis de interesse, é possível notar que MAQ, anteriormente significante a um nível de confiança de $90 \%$ frente a AUT, deixa de apresentar tal relação linear estatisticamente significativa. Este resultado pode servir de contestação para o sinal negativo percebido previamente que contrariava a literatura existente sobre o maquiavelismo. 
Por sua vez, NAR e PSI mantêm as mesmas relações de significância estatística percebidas nas estimações por MQO, além dos mesmos sinais e de coeficientes com magnitudes muito similares.

Esse conjunto de resultados, portanto, denota maior consistência aos resultados percebidos nas estimações por MQO ao indicar que havia pouca influência de valores extremos, haja vista que os resultados baseados na mediana foram preservados quase em sua totalidade.

\section{Considerações Finais}

O ceticismo profissional é uma característica desejável para o adequado exercício da profissão de auditor, segundo dispositivos de órgãos reguladores e acadêmicos. Contudo, é sabido também que tal atributo é de difícil mensuração.

Diante da relevância e complexidade do ceticismo profissional dos auditores, algumas pesquisas buscaram explicar fatores determinantes desta variável, sendo os traços de personalidade dos auditores uma vertente frequente nesse sentido. Todavia, não haviam sido realizados, até então, estudos empíricos considerando os traços de personalidade socialmente indesejáveis. Este gap é aparentemente relevante, conforme Hobson et al. (2020), porque a psicologia sugere que as diferentes personalidades dos auditores tendem a influenciar a qualidade de seus serviços profissionais.

E, nessa esteira, a presente pesquisa buscou analisar a influência dos "traços sombrios" de personalidade no ceticismo profissional de auditores independentes do Brasil.

De uma forma geral, há sugestão de que: a) o maquiavelismo não seja capaz de influenciar positivamente o ceticismo profissional e que, inclusive, ele pode vir a prejudicar esta qualidade na esfera da autonomia dos auditores; b) o narcisismo dos auditores independentes pode vir a trazer benefícios em termos de ceticismo profissional ao elevar a autoestima e a capacidade de questionamento desses profissionais; e c) a psicopatia presente no perfil de auditores independentes também não seria capaz de auxiliar a formação de um caráter cético no exercício de suas profissões. Este traço de personalidade pode, ainda, segundo os resultados da pesquisa, mitigar a condição de existência do ceticismo profissional ao reduzir a autoestima dos profissionais em questão.

Presume-se que esta pesquisa esteja limitada em certa instância por não considerar os traços de personalidade desejáveis dos auditores de forma conjunta com seus traços não desejáveis e também por não explorar as especificidades de cada indivíduo diante de questionamentos abertos.

Assim, sugere-se que futuras pesquisas busquem analisar a relação entre os traços sombrios de personalidade dos auditores e o ceticismo profissional diante de uma abordagem interpretativista, fato que habilitaria os sujeitos de pesquisa a relatarem como suas vivências pessoais e profissionais implicam em suas posições de ceticismo.

\section{Referências}

Bell, T. B., Peecher, M. E., \& Solomon, I. (2005). The 21st century public company audit: conceptuals elements of kpmg's global audit methodology. New Jersey: KPMG International.

Bistaffa, B. C. (2010). Incorporação de indicadores categóricos ordinais em modelos de equações estruturais (Dissertação de Mestrado, Universidade de São Paulo). Recuperado de: https://teses.usp.br/teses/ disponiveis/45/45133/tde-09022011-110229/publico/dissertacao_bruno_cesar_bistaffa.pdf. Em 17 de Fevereiro de 2020.

Bobek, D. D., Hageman, A. M., \& Radtke, R. R. (2015). The effects of professional role, decision context, and gender on the ethical decision making of public accounting professionals. Behavioral Research in Accounting, 27(1), pp. 55-78.Doi: 10.2308/bria-51090 
Campbell, W. K., \& Foster, C. A. (2002). Narcissism and commitment in romantic relationships: An investment model analysis. Personality and social psychology bulletin, 28(4), pp. 484-495. Doi: $10.1177 / 0146167202287006$

Christie, R.; Geis, F. L. (1970).Studies in Machiavellianism(1. Ed.). New York: Academic Press.

Cleckley, H. (1976). The mask of sanity: An attempt to clarify some issues about the so-called psychopathic personality (5. Ed.). St. Louis (Missouri): Mosby.

Crockatt, P. (2006). Freud's 'On narcissism: an introduction'. Journal of child psychotherapy, 32(1), pp. 4-20.

Cohen, J. R., Dalton, D. W., \& Harp, N. L. (2017). Neutral and presumptive doubt perspectives of professional skepticism and auditor job outcomes. Accounting, Organizationsand Society, pp. 62, 1-20.Doi: 10.1016/j.aos.2017.08.003

Conselho Federal de Contabilidade (2016). NBC TA 200 (R1): Objetivos gerais do auditor independente e a condução da auditoria em conformidade com normas de auditoria. Recuperado de: http://www1. cfc.org.br/sisweb/SRE/docs/NBCTA200(R1).pdf. Em 23 de Janeiro de 2020.

Conselho Federal de Contabilidade (2016). NBC TA 240 (R1): Responsabilidade do auditor em relação a fraude, no contexto da auditoria de demonstrações contábeis. Recuperado de: http://www1.cfc.org. br/sisweb/SRE/docs/NBCTA240(R1).pdf. Em 23 de Janeiro de 2020.

Cunha, P. R., Silva, C. T., Peyerl, D. A., \&Haveroth, J. (2019). Influência dos traços de personalidade no ceticismo profissional de auditores independentes. Revista de Contabilidade e Organizações, 13, pp. 1-14.Doi: 10.11606/issn.1982-6486.rco.2019.158537

DeAngelo, L. E. (1981). Auditor size and audit quality. Journal of accounting and economics, 3(3), pp. 183199.Doi: https://doi.org/10.1016/0165-4101(81)90002-1

D’Souza, M. F., \& Jones, D. N. (2017). Taxonomia da rede científica do DarkTriad: revelações no meio empresarial e contábil. Revista de Educação e Pesquisa em Contabilidade, 11(3), pp. 296-313.Doi: 10.17524/repec.v11i3.1588

D’Souza, M. F., \& de Lima, G. A. S. F. (2018). Escolha de carreira: o DarkTriad revela interesses de estudantes de Contabilidade. Revista de Contabilidade e Organizações, 12, pp. 1-21.Doi: 10.11606/ issn.1982-6486.rco.2018.151837

D’Souza, M. F., Lima, G. A. S. F., Jones, D. N., \& Carré, J. R. (2019). Eu ganho, a empresa ganha ou ganhamos juntos? Traços moderados do DarkTriad e a maximização de lucros. Revista Contabilidade e Finanças, 30(79), pp. 123-138.Doi: https://orcid.org/0000-0002-3196-5396

Duarte, F. C. L., Girão, L. F. A. P., \& Paulo, E. (2017). Avaliando Modelos Lineares de ValueRelevance: Eles Captam o que Deveriam Captar? Revista de Administração Contemporânea, 21(spe), pp. 110-134. Doi: 10.1590/1982-7849rac2017160202

Fávero, L. P. L., Belfiore, P. P., Silva, F. L. D., \& Chan, B. L. (2009). Análise de dados: modelagem multivariada para tomada de decisões. Rio de Janeiro: Elsevier.

Freud, S. (1914). On Narcissism: An introduction. London: Hogarth Press.

Gujarati, D. N.; \& Porter, D. C. (2011). Basic econometrics (5. Ed.). New York: McGraw-HiII.

Gustafson, S. B., \& Ritzer, D. R. (1995). The dark side of normal: A psychopathy-linked pattern called aberrant self-promotion. European journal of personality, 9(3), pp.147-183. Doi: https://doi. org/10.1002/per.2410090302

Hair, J. F., Anderson, R. E., Tatham, R. L., \& Black, W. C. (2005). MultivariateData analysis with readings. New Jersey: Prentice Hall.

Hare, R. D., \& Neumann, C. S. (2008). Psychopathy as a clinical and empirical construct.Annual Review of Clinical. Psychology, 4, pp. 217-246. Doi: 10.1146/annurev.clinpsy.3.022806.091452 
Haveroth, J. Cunha, P. R. (2018). Influência do Estresse Ocupacional no Ceticismo Profissional de Auditores Independentes. Trabalho apresentado no XII Congresso ANPCONT, João Pessoa, Brasil. Recuperado de: http://anpcont.org.br/pdf/2018_MFC474.pdf. Em 11 de Fevereiro de 2020.

Hobson, J. L., Stern, M. T., \&Zimbelman, A. F. (2020). The Benefit of Mean Auditors: The Influence of Social Interaction and the Dark Triad on Unjustified Auditor Trust. Contemporary Accounting Research, Ahead of Print. Doi: 10.1111/1911-3846.12511

Holgado-Tello, F. P., Chacón-Moscoso, S., Barbero-García, I., \& Vila-Abad, E. (2010). Polychoric versus Pearson correlations in exploratory and confirmatory factor analysis of ordinal variables. Quality \& Quantity, 44(1), pp. 153-166. Doi: 10.1007/s11135-008-9190-y

Hurtt, R. K. (2010). Development of a scale to measure professional skepticism. Auditing: A Journal of Practice \& Theory, 29(1), pp. 149-171. Doi: 10.2308/aud.2010.29.1.149

Hurtt, R. K., Brown-Liburd, H., Earley, C. E., \& Krishnamoorthy, G. (2013). Research on auditor professional skepticism: Literature synthesis and opportunities for future research. Auditing: A Journal of Practice \& Theory, 32(sp1), pp. 45-97. Doi: 10.2308/ajpt-50361

Hussin, S. A. H. S., Saleh, N. M., \& Al-smady, A. A. (2019). Auditor Demographic Factors and Dimensions of Auditors' Skepticism in Jordan. Asian Journal of Accounting and Governance, 11, pp. 39-48. Doi: 10.17576/AJAG-2018-11-04)

Jones, D. N., \&Paulhus, D. L. (2014). Introducing the short dark triad (SD3) a brief measure of dark personality traits. Assessment, 21(1), pp. 28-41.Doi: https://doi.org/10.1177/1073191113514105

Lucena, W. G. L., Fernandes, M. S. A., \& Silva, J. D. G. (2011). A contabilidade comportamental e os efeitos cognitivos no processo decisório: uma amostra com operadores da contabilidade. Revista Universo Contábil, 7(3), pp. 41-58. Doi: DOI:10.4270/RUC.2011321

Majors, T. M. (2016). The interaction of communicating measurement uncertainty and the dark triad on managers' reporting decisions. The Accounting Review, 91(3), pp. 973-992. Doi: 10.2308/accr-51276

Maroco, J., \& Garcia-Marques, T. (2006). Qual a fiabilidade do alfa de Cronbach? Questões antigas e soluções modernas? Laboratório de psicologia, 4(1), pp. 65-90. Recuperado em https://core.ac.uk/ reader $/ 70647773$

Maxwell, K., Donnellan, M. B., Hopwood, C. J., \& Ackerman, R. A. (2011). The two faces of Narcissus? An empirical comparison of the Narcissistic Personality Inventory and the Pathological Narcissism Inventory. Personality and Individual Differences, 50(5), pp. 577-582. Doi: 10.1016/j.paid.2010.11.031

McHoskey, J. (1995). Narcissism and machiavellianism. Psychological reports, 77(3), pp.755-759. Doi: https://doi.org/10.2466/pr0.1995.77.3.755

McHoskey, J. W., Worzel, W., \&Szyarto, C. (1998). Machiavellianism and psychopathy. Journal of personality and social psychology, 74(1), pp. 192-210. Doi: 10.1037//0022-3514.74.1.192

McIlwain, D. (2003). Bypassing empathy: A Machiavellian theory of mind and sneaky power. In Repacholi, B.;\&Slaughter, V. Individual Differences in Theory of Mind: Implications for Typical and Atypical Development. Hove: Psychology Press.Doi: 10.4324/9780203488508

Mendes, P. C. M., Niyama, J. K., \& Silva, C. A. T. (2018). A Percepção dos Auditores na Mensuração dos Instrumentos Financeiros a Valor Justo nas Instituições Financeiras. Brazilian Business Review, 15(4), pp. 363-381. Doi: https://doi.org/10.15728/bbr.2018.15.4.4

Miller, J. D., \& Campbell, W. K. (2008). Comparing clinical and social-personality conceptualizations of narcissism. Journal of personality, 76(3), pp. 449-476. Doi: 10.1111/j.1467-6494.2008.00492.x 
Mubako, G., \& O’Donnell, E. (2018). Effect of fraud risk assessments on auditor skepticism: Unintended consequences on evidence evaluation. International Journal of Auditing, 22(1), pp. 55-64. Doi: 10.1111/ijau.12104

Mujis, D. (2011).Doing quantitative research in education with SPSS. London: Sage Publications.

Murphy, C. O.; Davidshofer, K. R. (2005). Psychological testing: principles and applications. New Jersey: Pearson/Prentice Hall.

Muzel, V. P. (2018). A educação continuada no Brasil na perspectiva da carreira do auditor independente (Dissertação de Mestrado, Universidade de São Paulo).Recuperado de: https://teses.usp.br/teses/ disponiveis/12/12136/tde-29082018-152250/publico/CorrigidoVania.pdf

Nelson, G., \& Gilbertson, D. (1991). Machiavellianism revisited. Journal of Business Ethics, 10(8), pp. 633639.Recuperado em: https://www.jstor.org/stable/25072196

Nelson, M. W. (2009). A model and literature review of professional skepticism in auditing. Auditing: A Journal of Practice \& Theory, 28(2), pp. 1-34. Doi: 10.2308/aud.2009.28.2.1

Nolder, C. J., \&Kadous, K. (2018). Grounding the professional skepticism construct in mindset and attitude theory: A way forward. Accounting, Organizations and Society, 67, pp. 1-14. Doi: 10.1016/j. aos.2018.03.010

Nunnally, J. C.; \& Bernstein, I. H. (1994). The theory of measurement error. Psychometric theory (3. Ed.). New York: Mcgraw-Hill.

Ohlson, J. A., \& Kim, S. (2015). Linear Valuation Without OLS: The Theil-Sen Estimation Approach. Review of Accounting Studies, 20(1), pp. 395-435. Doi: 10.2139/ssrn.2276927

Olsen, C., \& Gold, A. (2018). Future research directions at the intersection between cognitive neuroscience research and auditors' professional skepticism. Journal of Accounting literature, 41, pp. 127-141. Doi: 10.1016/j.acclit.2018.03.006

Paal, T., \&Bereczkei, T. (2007). Adult theory of mind, cooperation, Machiavellianism: The effect of mindreading on social relations. Personality and individual differences, 43(3), pp. 541-551. Doi: 10.1016/j.paid.2006.12.021

Paulhus, D. L., \& Williams, K. M. (2002). The dark triad of personality: Narcissism, Machiavellianism, and psychopathy. Journal of research in personality, 36(6), pp.556-563. Doi: https://doi.org/10.1016/ S0092-6566(02)00505-6

Pincus, A. L., \&Lukowitsky, M. R. (2010). Pathological narcissism and narcissistic personality disorder. Annual review of clinical psychology, 6, pp. 421-446. Doi: 10.1146/annurev.clinpsy.121208.131215

Pulver, S. E. (1970). Narcissism: The term and the concept. Journal of the American Psychoanalytic Association, 18(2), pp. 319-341. Doi: https://doi.org/10.1177/000306517001800204

Quadackers, L., Groot, T., \& Wright, A. (2014). Auditors' professional skepticism: Neutrality versus presumptive doubt. Contemporary accounting research, 31(3), pp. 639-657. Doi: 10.2139/ ssrn. 2162947

Ralph, P. L. (1973). The Renaissance in Perspective. New York: St. Martin's Press.

Rhodewalt, F.; \&Peterson, P. (2009). Narcissism. In Leary, M. R.; \& Hoyle, R. H. Handbook of individual differences in social behavior. New York: Guilford Press.

Rosenthal, S. A., \& Hooley, J. M. (2010). Narcissism assessment in social-personality research: Does the association between narcissism and psychological health result from a confound with self-esteem? Journal of Research in Personality, 44(4), pp. 453-465. Doi: 10.1016/j.jrp.2010.05.008 
Steppan, A. I. B., Santiago, J. S., Silva, J. D. G., Cavalcante, P. R. N., \& Silva, C. A. T. (2015). Julgamento na auditoria: um estudo das características das pesquisas científicas. Ciências \& Cognição, 20(1). Recuperado em: https://www.researchgate.net/publication/339826980_JULGAMENTO_NA_ AUDITORIA_UM_ESTUDO_DAS_CARACTERISTICAS_DAS_PESQUISAS_CIENTIFICAS

Stevens, E., Moroney, R., \& Webster, J. (2019). Professional skepticism: The combined effect of partner style and team identity salience. International Journal of Auditing, 23(2), pp. 279-291. Doi: https:// doi.org/10.1111/ijau.12161

Viding, E., \& McCrory, E. J. (2018). Understanding the development of psychopathy: progress and challenges. Psychological medicine, 48(4), pp. 566-577. Doi: 10.1017/S0033291717002847

Volmer, J., Koch, I. K., \&Göritz, A. S. (2016). The bright and dark sides of leaders' dark triad traits: Effects on subordinates' career success and well-being. Personality and Individual Differences, 101, pp. 413418. Doi: 10.1016/j.paid.2016.06.046

Wallace, H. M., \& Baumeister, R. F. (2002). The performance of narcissists rises and falls with perceived opportunity for glory. Journal of personality and social psychology, 82(5), pp. 819-834. Doi: 10.1037/0022-3514.82.5.819

Wexler, M. N. (2008). Conjectures on systemic psychopathy: reframing the contemporary corporation. Society and Business Review, 3(3), 224-238. Doi: 10.1108/17465680810907305

Wilson, D. S., Near, D., \& Miller, R. R. (1996). Machiavellianism: A synthesis of the evolutionary and psychological literatures. Psychological bulletin, 119(2), pp. 285-299. Doi: 10.1037//00332909.119.2.285 